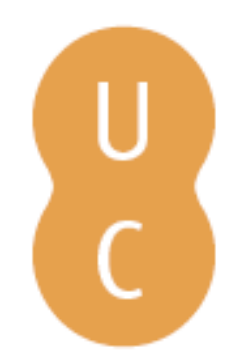

\title{
Rompalina
}

Algumas experiências de divulgação da matemática na imprensa portuguesa

Autor(es): $\quad$ Crato, Nuno

Publicado por: Imprensa da Universidade de Coimbra; Gravida

URL

persistente: URI:http://hdl.handle.net/10316.2/32612

DOI: $\quad$ DOI:http://dx.doi.org/10.14195/978-989-26-0485-5_2

Accessed : $\quad$ 26-Apr-2023 13:52:24

A navegação consulta e descarregamento dos títulos inseridos nas Bibliotecas Digitais UC Digitalis, UC Pombalina e UC Impactum, pressupõem a aceitação plena e sem reservas dos Termos e Condições de Uso destas Bibliotecas Digitais, disponíveis em https://digitalis.uc.pt/pt-pt/termos.

Conforme exposto nos referidos Termos e Condições de Uso, o descarregamento de títulos de acesso restrito requer uma licença válida de autorização devendo o utilizador aceder ao(s) documento(s) a partir de um endereço de IP da instituição detentora da supramencionada licença.

Ao utilizador é apenas permitido o descarregamento para uso pessoal, pelo que o emprego do(s) título(s) descarregado(s) para outro fim, designadamente comercial, carece de autorização do respetivo autor ou editor da obra.

Na medida em que todas as obras da UC Digitalis se encontram protegidas pelo Código do Direito de Autor e Direitos Conexos e demais legislação aplicável, toda a cópia, parcial ou total, deste documento, nos casos em que é legalmente admitida, deverá conter ou fazer-se acompanhar por este aviso. 
(Página deixada propositadamente em branco) 
MARIA PAULA SERRA DE OLIVEIRA

Coordenadora

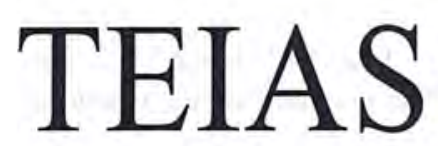

MATEMÁTICAS

Frentes na Ciência e na Sociedade 
(C) Gradiva - Publicações, L. da / Imprensa da Universidade de Coimbra, 2004 Coordenação editorial: Maria Paula Serra de Oliveira

Tradução: Artur Soares Alves

Carlota Isabel Leitão Pires Simões

Francisco José Craveiro de Carvalho

João Filipe Cortez Rodrigues Queiró

José Miguel Dordio Martinho de Almeida Urbano

Lia Sandra dos Santos

Mário da Silva Rosa

Paulo Eduardo Aragão Aleixo Neves de Oliveira

Revisão do texto: Isabel Pedrome

Capa: António Barros [Imprensa da Universidade. Coimbra], com imagem de

E. M. de Melo e Castro, "Fract 010 explod MC", Dezembro de 2003

[Fractal original gerado no Fractint com tratamento no Photoshop 7.0]

Infografia: Estúdios Estímulus [design]

Paginação: António Resende e Victor Hugo Fernandes

Impressão e acabamento: G.C. - Gráfica de Coimbra, L. da

Reservados os direitos para Portugal por:

Gradiva - Publicações, L. ${ }^{\text {da }}$ e Imprensa da Universidade de Coimbra

Gradiva - Publicações, L. ${ }^{d a}$

Rua Almeida e Sousa, 21, r/c, esq. • 1399-041 Lisboa

Telefs. $213974067 / 8 \cdot 213971357 \cdot 213953470$

Fax $213953471 \cdot$ Email: gradiva@ip.pt

URL: http://www.gradiva.pt

Imprensa da Universidade de Coimbra

Rua Antero de Quental, 195 • 3000-033 Coimbra

Telefs. 351239853110

Fax 3512398531 19 e-mail: fjrpress@ci.uc.pt

URL: http://www.imp.uc.pt

ISBN: 972-662-970-5

1." edição: Maio de 2004

Depósito legal n. ${ }^{\circ} 210431 / 04$

OBRA PUBLICADA COM O PATROCÍNIO DE:

CENTRO DE MATEMÁTICA DA UNIVERSIDADE DE COIMBRA DEPARTAMENTO DE MATEMÁTICA DA UNIVERSIDADE DE COIMBRA

FCT Fundação para a Ciência e a Tecnologia

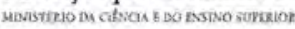


Nuno Crato

Departamento de Matemática do

Instituto Superior de Economia e Gestão

\section{Algumas experiências de divulgação da matemática na imprensa portuguesa}

Os cientistas e os académicos costumam queixar-se da comunicação social e dos jornalistas. Afirmam, e é em grande parte verdade, que a imprensa não cobre as suas actividades, não dedica espaço à divulgação e ao noticiário científico e, quando o faz, comete imprecisões e erros grosseiros. Todos têm histórias para contar. Uns citam disparates crassos que apareceram na imprensa. Outros referem alturas em que foram citados de forma enganadora. A maioria queixa-se da falta de cobertura das actividades de natureza científica, que são preteridas em favor do fait divers, dos escândalos do momento ou de temas de importância secundária. É difícil encontrar um cientista ou académico que não critique asperamente os jornalistas.

Do outro lado encontramos jornalistas que se queixam dos académicos. Dizem que estes são incompreensíveis e não fazem um esforço para se tornarem acessiveis. Acusam-nos de serem intransigentes nos pormenores e de não perceberem que a imprensa tem os seus critérios e necessita de transformar o acontecimento em notícia apelativa, relevante e actual, actividade na qual os cientistas são altamente ignorantes.

Esta incompreensão entre os dois campos é velha e já foi discutida até à exaustão. Parece inútil continuar a bater nas mesmas teclas sem 
tentar estabelecer pontes entre os dois campos. O que é preciso é procurar ultrapassar incompreensões entre académicos e jornalistas, pois ambos têm a lucrar com uma maior cooperação: os jornalistas com uma informação mais actual, rigorosa e rica e os cientistas com o interesse do público, com a divulgação das suas actividades e com o prestígio da sua profissão.

\section{O QUE OS CIENTISTAS E OS ACADÉMICOS DEVEM SABER SOBRE JORNALISMO}

O jornalismo é uma arte com algumas regras e técnicas precisas. $\mathrm{O}$ bom jornalismo é uma arte difícil. Para o cientista ver a sua actividade divulgada tem de saber dar ao jornalista informações actualizadas, precisas e aliciantes.

Os critérios que habitualmente se enunciam quando se fala na selecção da notícia são a actualidade, o significado e o interesse público. A actualidade é fácil de entender: ao contrário dos académicos, o público não está interessado em notícias ou artigos intemporais. Lê-se o jornal para saber o que está a acontecer, para pertencer ao grupo de pessoas informadas, para compreender a evolução do mundo, para ter tema de conversa. O segundo critério, do significado, é entendido como a relevância perceptível da peça jornalística, não as suas implicações remotas ou para um grupo restrito. O terceiro critério, do interesse do público, é imperioso: a imprensa não pode sobreviver sem leitores.

É possível escrever uma boa peça jornalística que não satisfaça algum destes critérios, mas não é possível escrever uma que falhe nos três. Ao procurar a actualidade, o cientista ou o divulgador deve fornecer informações recentes, sobre realizações acontecidas num passado muito próximo ou a acontecer num futuro também muito próximo. Muitas vezes, a actualidade não está no cerne da peça jornalística, mas apenas na sua apresentação - o artigo torna-se actual não porque fale de uma descoberta recente, mas porque referencia problemas sentidos na actualidade. Tornar actual uma peça de divulgação científica é uma arte.

O significado pode ser entendido no seu aspecto mais imediato, mas o divulgador deve saber que essa visão é errada. As pessoas não se interessam apenas pelo que as afecta no dia-a-dia, mas também pelo que afecta a sua compreensão do mundo. O público está muitas vezes mais interessado nas novas descobertas sobre a idade do universo do que em novos métodos de tratamento do cancro. Dar significado visível a uma descoberta aparentemente irrelevante é outra arte da divulgação. 
O interesse do público é um critério disciplinador do cientista ou do académico que pretende fazer divulgação científica. Não deve ser entendido como uma limitação, mas sim como um desafio. $\mathrm{O}$ interesse do público é menos imediatista e limitado do que muitas vezes se supõe. As pessoas estão interessadas em alargar a sua cultura científica, querem saber o que são fractais e o que é o caos, querem compreender a radioactividade, a Internet e as viagens interplanetárias.

\section{O MITO DO DESINTERESSE DO PÚBLICO}

Julgamos, muitas vezes, que o público está pouco interessado na actividade científica e cultural e que está mais atento a notícias sensacionalistas, a intrigas e a pormenores secundários da vida. Se isso pode ser verdade em termos gerais, a realidade é que há uma parcela importante do público, talvez sobretudo do público jovem, que está atenta ao noticiário científico e que tenta seguir as descobertas importantes do nosso tempo, assim como as polémicas cientificas e culturais.

O que acontece é que há muita gente que se desinteressa daquilo que nós, cientistas e académicos, julgamos importante, pela simples razão de que não sabemos chegar a essas pessoas e não percebemos que a divulgação científica é radicalmente diferente da actividade de ensino académico.

Há sinais bem visíveis do interesse do público. Um bom exemplo é o crescente interesse pela literatura de divulgação científica. Praticamente todas as grandes editoras portuguesas começaram a publicar livros dos melhores autores de divulgação. Publicam-se hoje incomparavelmente mais obras sobre ciência do que há meia dúzia de anos.

Outro factor novo e entusiasmante é a proliferação de planetários, centros de Ciência Viva, museus de ciência e locais similares que aparecem um pouco por todo o país. É certo que esses locais são menos visitados do que muitos dos seus congéneres estrangeiros, nomeadamente norte-americanos. Mas a verdade é que são muito mais frequentados do que muitos museus tradicionais.

Finalmente, a própria imprensa dedica hoje muito mais páginas à ciência do que ainda há poucos anos. Praticamente todos os grandes diários e semanários têm secções de ciência ou de ciência e ambiente.

$\mathrm{O}$ que se passa é que o interesse que agora desperta é um interesse novo, muito diferente do que existia há algumas gerações atrás. Quando se organizam conferências e debates sobre reflexões culturais e científicas abstractas, o público é reduzido. Quando se montam telescópios para observar as manchas solares, o público é numeroso. Será que esse facto 
é negativo? Será que é triste que as pessoas se desinteressem de debates sobre «a ética da ciência e a ciência da ética», enquanto se interessam por observar as maravilhas do céu através de telescópios?

A resposta a esta questão é decisiva para saber em que ponto nos colocamos quanto ao interesse do público e à divulgação científica que nos interessa fazer. Julgo que o público tem razão e que as discussões vagas de temas fluidos são pouco relevantes, enquanto o conhecimento e a participação directa é educativa e estimulante. É este tipo de divulgação científica que me interessa fazer e por isso julgo que o público nos envia sinais positivos.

\section{O MITO DO DESINTERESSE DA IMPRENSA}

É certo que a comunicação social não dá o relevo que julgamos merecido à actividade científica. É certo que a imprensa não relata com rigor muita actividade científica e cultural que gostaríamos de ver mais difundida. É certo que os noticiários dão maior destaque a temas que consideramos menores, em detrimento da actividade académica, científica e de divulgação.

Mas não é menos certo que os jornalistas estão receptivos à informação científica e à ideia de a apresentar. O problema é que não é fácil fazê-lo. Qualquer jornalista precisa de fontes. Ora as fontes nacionais são habitualmente pobres. Basta perguntar o que fazemos nas universidades e laboratórios de investigação para preparar uma informação completa, actualizada, simultaneamente rigorosa e acessível e que a imprensa possa utilizar. O que fazemos é pouco ou nada. Se olharmos para as fontes internacionais, nomeadamente as melhores, veremos como estamos a anos-luz de distância de produzir uma informação que a imprensa possa utilizar. Olhe-se para a página na Internet da NASA, por exemplo, e leiam-se as notícias e comunicados de imprensa que aí aparecem. São documentos completos, informativos, acompanhados de ilustrações magníficas e de diagramas rigorosos. São textos apelativos, bem escritos, com títulos e subtítulos sugestivos, semeados de declarações de cientistas e de informações interessantes. Em anexo vêm habitualmente pormenores complementares, referências de outras fontes e sugestões de pistas para o jornalista alargar a sua notícia.

Parece pois que bastaria à imprensa copiar ou adaptar essas notícias internacionais para produzir um noticiário científico muito mais interessante. Isso é verdade e explica, em parte, a razão por que as páginas dedicadas à ciência têm uma maioria de fontes estrangeiras. Mas os 
jornalistas não podem adaptar muitas dessas notícias porque não as sabem traduzir em português. É culpa deles e da sua ignorância? Não, mais uma vez a culpa é nossa, pois os intelectuais e académicos não souberam ainda produzir dicionários completos e actualizados, nomeadamente dos termos científicos. Tentemos traduzir do inglês uma notícia científica. Assim como um matemático teria grandes dificuldades em traduzir termos de biologia e um astrónomo não conseguiria traduzir muita da nomenclatura própria da medicina, também um jornalista receia traduzir certas notícias científicas. Infelizmente, os dicionários que existem são muito incompletos, sobretudo em termos cientificos. Será culpa dos jornalistas ou nossa, dos académicos?

\section{A INSUPORTẢVEL VAIDADE DO SER ${ }^{1}$}

Falemos agora de alguns aspectos importantes a ter em conta pelos que se interessam pela divulgação científica. $\mathrm{O}$ primeiro desses aspectos é a clareza da escrita.

Trata-se de um aspecto central e fundamentalissimo. Os intelectuais literatos conseguem (felizmente cada vez menos!) fazer publicar críticas de cinema ou de literatura que são absolutamente incompreensiveis para o público. Muitas vezes, podem-se ler críticas de cinema que não têm um mínimo de informação e que não conseguem transmitir ao leitor uma única

1 A expressão «insustentável leveza do ser» é utilizada à exaustão pelos nossos críticos. É uma referência ao título de um livro célebre do escritor checo Milan Kundera, que, em francês, uma das línguas desse autor, e na qual esta obra primeiramente apareceu, em 1984, se intitula L'insoutenable légèreté de l'être. Em checo o livro intitula-se Nesnesitelná lehkost by tí, o que significa exactamente o mesmo. Em inglês, o título apareceu correctamente traduzido como The Unbearable Lightness of Being. Em português, o livro e o filme apareceram com o incompreensível título A Insustentável Leveza do Ser. Pois é desse incompreensivel título que muitos intelectuais tanto gostam.

$\mathrm{O}$ erro de tradução é evidente: «insoutenable», tal como «nesnesitelná» e «unbearable», significa «insuportável» ou «intolerável», e não «insustentável». No português falado e escrito, «insuportável» é aquilo que não se pode aguentar ou a que não se consegue resistir, enquanto «insustentável» significa aquilo que não se pode defender ou não se consegue segurar. A «leveza do ser» pode ser difícil de encarar, mas certamente não é fácil nem difícil de segurar... Quando um intelectual literato reflecte sobre a «insustentável leveza do ser» está provavelmente a falar de... nada. 
ideia sobre o filme em causa. O mesmo acontece com muita crítica literária. Por alguma razão estranha - talvez enraizada na ideia absurda de que a cultura se identifica com o inatingível e com as humanidades e não com a ciência -, esses críticos conseguem publicar peças jornalísticas que são autênticos atentados à inteligência do público e ao jornalismo. Mas essas peças incompreensiveis continuam a aparecer.

Mesmo que a imprensa portuguesa nos deixasse utilizar o mesmo estilo hermético nas peças cientificas (felizmente, não deixa!), não é isso que queremos com a divulgação científica. É importante perceber que os textos jornalísticos incompreensíveis não denotam cultura nem inteligência por parte dos seus autores, mas apenas sobranceria, pedantismo e ignorância. Quando alguém não sabe explicar um tema em palavras simples, esse alguém quase certamente não o percebe e esconde a sua ignorância e a falta de clareza das suas ideias sob a capa de frases rebuscadas, de uma terminologia hermética e de conceitos abstractos que tão a propósito vêm nesse artigo como em qualquer outro. Basta atentar no jargão de alguns críticos culturais para verificar a sua falta de imaginação, a fluidez dos seus conceitos e a sua ignorância. As frases feitas rodam sempre em torno de uma combinatória de um léxico muito limitado: «o último romântico», «o rigor do olhar», «uma leitura poemática», «os vectores da leitura», «a insustentável leveza do ser», etc.

Devemos rir-nos destas peças herméticas. É saudável rir-nos e prometer a nós mesmos não cair nestes embustes. Não é sinal de cultura ler ou ouvir disparates com ar inteligente. Muito menos é sinal de cultura aproveitar a imprensa para destilar uma pretensa erudição repleta de frases feitas.

\section{COMO SE PODE SER CLARO}

Ser claro não é fácil. É difícil, muito difícil. Quando alguém começa conscienciosamente a escrever, é natural que desenvolva uma preocupação extrema pelo rigor do português, Essa preocupação é importante, mas o purismo pode ser um objectivo secundário. Ainda hoje não escrevo «detalhe», pois é um francesismo a que prefiro «pormenor» ou «minúcia». Mas não me choca que esse termo apareça. Utilizo outros termos igualmente impuros, tais como «currículos», pois pouca gente se lembra (ou sabe) que «curricula» é o plural do latim «curriculum». Quer dizer, a clareza parece ser mais importante do que o purismo ortográfico.

O que é verdadeiramente importante é que as ideias sejam claras, apareçam em frases simples, com termos simples e conhecidos de todos, 
e que se sigam logicamente de período para período e de parágrafo para parágrafo. No fundo, escrever claramente não é impossível. Trata-se de evitar períodos longos, de incluir apenas uma ideia em cada frase e de escrever com o objectivo de se ser entendido.

Onde o jornalismo científico tem problemas próprios é no uso de jargão e na simplificação das ideias. Não se pode escrever um artigo jornalístico como se escreve um artigo científico especializado. Há, quase sempre, concessões inevitáveis à clareza que chocam o nosso espírito científico. Se é preciso falar em funções contínuas, como se pode traduzir essa ideia num artigo jornalístico? Pode dizer-se que se trata de funções que podem ser desenhadas sem nunca levantar o lápis do papel; no entanto, nós sabemos que essa definição não é correcta. Muitas vezes não é possível incluir definições correctas no texto. Que se pode então fazer?

Não há uma resposta geral, pois o problema deve ser visto caso a caso. $\mathrm{O}$ académico tem habitualmente pruridos, pois teme que os seus pares considerem ignorância a não utilização dos termos e das definições mais correctas. Esses receios têm de ser ultrapassados, pois são paralisantes. Não se escreve para se ser bem visto pelos colegas, mas para se ser entendido pelo público. Felizmente, cada vez é maior o número de académicos e cientistas que o compreendem.

Se quisermos estabelecer uma regra geral, deveremos recomendar que se limitem os termos técnicos e que se expliquem os conceitos, que não se apresentem como definições completas o que são apenas intuições e que se deixe entrever a maior complexidade do tema sem defraudar o leitor.

\section{A IMPORTÂNCIA do ESPíRITO CIENTÍFICO}

Há várias razões pelas quais o jornalismo científico é importante. Uma delas é despertar vocações científicas nos mais jovens. Outra é informar os interessados. Outra, ainda, é despertar o espírito crítico e democrático que são apanágios da ciência.

Há variadas maneiras de escrever peças científicas. Uma das mais interessantes é a que fornece simultaneamente informações factuais actualizadas, desperta interesse por seguir os desenvolvimentos na área, enquadra a notícia no curso histórico da batalha por compreender determinado fenómeno e permite relacionar os factos com vivências do leitor. Fazer tudo isto pode ser muito ambicioso, mas é importante ter em conta estes objectivos.

Ao transmitir informações actualizadas estamos a cumprir um dos requisitos fundamentais do jornalismo, mas estamos também a interessar 
o leitor em seguir os desenvolvimentos na área. Ao enquadrar a notícia no curso histórico do desenvolvimento da ciência, estamos a mostrar que a actividade cientifica não é uma actividade fechada, que as descobertas nunca são definitivas, mas sim passos no avanço do conhecimento científico.

É muito importante que os cidadãos percebam estes aspectos do jornalismo de divulgação científica. Nada é mais irritante do que as notícias de novas descobertas que levam o leitor a concluir que afinal os cientistas apenas se enganam. Este tipo de notícias aparece com grande frequência, sobretudo quando se trata de descobertas clínicas. Alguns jornalistas, estupidamente, adoram dar a entender que os médicos nada sabem. Vêem-se com frequência notícias que contradizem afirmações anteriores: «Agora os médicos descobriram que o açúcar faz bem, quando há tempos diziam que fazia mal. Em quem se pode confiar?» Pois o que o jornalista deveria ser capaz de explicar é que os investigadores tinham razão quando diziam que o açúcar faz mal e voltaram a ter razão quando disseram que o açúcar faz bem. Como é isso possível? Naturalmente, quando se descobriram os malefícios do açúcar, estava-se a contrariar certos hábitos de consumo exagerado. Quando se descobriram os beneficios do açúcar estava-se a dizer que, em certas condições, o incremento desse consumo pode ser benéfico. Quais as condições num e noutro caso? Para que tipo de pessoas? Em que doses? Em que alturas? É isso que cabe aos jornalistas científicos explicar. De outra forma, a sua notícia é irrelevante e mal informada.

Finalmente, ao referir a notícia cientifica à vivência das pessoas está-se a lançar sementes muito mais fecundas do que as que podem ficar de uma notícia que apenas relata factos distantes. Não se trata apenas de dar exemplos e de transmitir as ideias de forma perceptível, embora isso seja importante $^{2}$. Trata-se de ajudar as pessoas a pensar, no dia-a-dia, com a informação cientifica que lhes é proporcionada.

Descobriu-se há pouco, por exemplo, que a ilusão visual de a Lua ser maior quando nasce deriva das referências do observador junto ao horizonte. É interessante informar o leitor dessa descoberta. Mas mais

${ }^{2}$ Numa peça de divulgação científica portuguesa lê-se, por exemplo, «a uma velocidade tal que ligaria Nova Iorque a Los Angeles em menos de quatro minutos». Não seria preferível falar antes de Lisboa e Roma, ou de cidades de localização e distância mais directamente sentida pelos leitores? Só que isso daria trabalho, obrigaria a calcular distâncias e a fazer contas, enquanto aproveitar a informação fornecida por fontes norte-americanas é mais simples. 
interessante ainda é sugerir observações que todos podem fazer e que confirmam a origem dessa ilusão óptica. Igualmente, ao provar a conjectura de Kepler sobre o empilhamento de esferas resolveu-se um problema velho de cinco séculos. Isso é interessante, mas ainda mais interessante é mostrar diagramas com o empilhamento óptimo de laranjas e desafiar o leitor a procurar empilhamentos alternativos. Outro exemplo ainda: o Sol passou agora (meados de 2000) por um máximo de actividade. É interessante explicar que esse máximo foi revelado pelas manchas solares. Igualmente interessante é explicar como a descoberta dessas manchas, nos princípios do século XVII, levou a romper com vários conceitos cosmológicos medievais. Também é curioso relatar brevemente o processo de descoberta do ciclo solar. Mas o mais interessante é mostrar fotografias de manchas e explicar ao leitor como pode, ele próprio, observar directamente essas formações solares.

O esforço de divulgação científica pode ajudar o público a compreender melhor o mundo. Poder-se-á desejar mais? 


\section{$\begin{array}{llllll}\text { C I E } & \mathbf{N} & \mathbf{C} & \mathbf{A}\end{array}$}

mitiram realizar com sucesso tarefas tão distintas como a programação de um voo a Marte, a previsão de resultados eleitorais, a explicação do funcionamento de alguns mecanismos do sistema nervoso, ou a abordagem critica de obras de arte e de textos literários. Da ciência à sociedade, dos grandes avanços técnicos à solidez de uma argumentação lógica, a Matemática constrói teias de uma imensa flexibilidade resultante do carácter universal da sua linguagem.

Neste livro, personalidades de diferentes universos dão o seu testemunho sobre a forma como usam as teias matemáticas para tecer a sua própria visão do mundo.

Maria Paula Serra de Oliveira é professora de Matemática na Faculdade de Ciências e Tecnologia da Universidade de Coimbra. 